\title{
Exploring Indian Middle School Students' Conceptions of the Environment Using the Draw-an-Environment Test
}

\author{
Leslie Elizabeth Sprong \\ Global Education Cooperation, Seoul National University, \\ o8826 Seoul, Republic of Korea \\ lesliesprong@gmail.com
}

\author{
Sonya N. Martin \\ Corresponding author, \\ Department of Earth Science Education, Seoul National University, \\ o8226 Seoul, Republic of Korea \\ sonya_martin@fastmail.com
}

Received: 15 February 2020 | Revised: 19 May 2020, 13 June 2020 | Accepted: 13 June 2020

\begin{abstract}
Quality environmental education (EE) is key for supporting sustainable development and use of resources. Educators in rural India face considerable challenges to teach EE in K-12 school settings. This study took place in Assam in Northeast India where non-governmental organization (NGO) educators are working to develop an EE program for students in rural areas. To reveal students' perceptions of the environment, researchers administered the Draw-an-Environment Test (DAET) to 277 middle school students in government schools. Analysis of students' drawings of the environment revealed that while students recognized humans have an impact on the environment, they did not fully understand the impact could often be negative and drawings did not necessarily reflect the reality of the local environment. Implications for how these findings can be used to develop responsive EE curriculum that challenges and extends students' conceptions of the environment and the need for future research are discussed.
\end{abstract}




\section{Keywords}

Environmental education (EE) - Northeast India - Draw-an-Environment Test (DAET) - responsive curriculum

\section{Introduction}

India has the world's second-largest population and its rapid development has resulted in vast consumption of natural resources. Environmental damage and climate change are serious consequences of unsustainable development practices. In June 2019, India faced not only one of the worst droughts in its history, but also immense flooding in large parts of the country due to climate change (Haynes, 2019). Unsustainable development practices, such as clear-cutting forests and giving land developers the rights to pave over natural bodies of water are expected to have wide-ranging negative effects on both the environment and the citizens of India (Denton \& Sengupta, 2019). Left unchecked, such practices are predicted to have a profoundly negative impact on millions of people living in New Delhi and Chennai as scientists predict these cities will run out of water within the next decade.

For development to be sustainable, the toll on environment and natural resource usage needs to be carefully managed (Pachauri, 2004). A key factor in countering these issues and supporting sustainable development and resource use is quality environmental education ( $\mathrm{EE}$ ). EE can and should be used to motivate and empower people to change their behaviors and take action towards sustainable development (Sauvé, 1996). There is an urgent need for improving $\mathrm{EE}$ in India so that citizens can take appropriate action to improve the quality of the environment and to aid in sustainable development (Gupta, 2002). India's Supreme Court first introduced EE as a compulsory subject in the formal education system in 2003, and since then, studies have shown a major shift in attitudes in the education system with teachers placing a stronger focus on teaching E E content in schools (Ravindranath, 2016; Sonowal, 2009).

However, the environmental educators in India face considerable challenges to educate students about environmental issues at local and national levels due to the sheer size and diversity of the country landscape and the more than 1.2 billion people representing many diverse cultures and languages (Ravindranath, 2016). Differences in the climate, geography, language, economy, and social life make creating a curriculum that is relevant to students in different local and regional contexts very difficult. This is problematic because effective E E should be connected to students' everyday lives. Studies have shown that an increase 
in environmental knowledge alone is not enough to help students to develop pro-environmental behaviors, such as conserving energy, recycling, and reducing consumption. Instead, education needs to also address situational factors that can have a strong influence on pro-environmental behaviors (Kollmuss \& Agyeman, 2002). In addition to lacking in culturally relevant curriculum materials to support EE programs, India's teachers also lack adequate material resources (e.g., blackboards, textbooks, and electricity), and few teachers have the content knowledge and pedagogical training needed to effectively teach $\mathrm{EE}$ (Siddiqui \& Khan, 2015). This is especially true in government schools, which tend to have less funding and fewer resources than private schools. As a result, it can be difficult for India's EE educators to implement meaningful lessons that support students to deeply reflect on attitudes and practices related to the environment.

Not only do educators need resources and training, they also need curriculum materials that are designed to reflect students' background knowledge and lived experiences. Educators have long argued the need to develop culturally relevant curriculum so that the knowledge being shared by teachers is relevant for those being taught. In the context of $\mathrm{EE}$, this would mean that teachers need both an understanding of their students' cultural backgrounds (Ladson-Billings, 1995) and knowledge about how their students perceive the environment, including students' attitudes towards and concerns about the environment. Unfortunately, environmental programs are generally designed and developed based on assumptions about students' perceptions of the environment (Loughland et al., 2000), rather than actual knowledge about how students perceive the environment. This can be attributed, in part, to a widespread practice by school systems to simply adopt curriculum materials that are generic in their coverage and presentation of science and EE content. Evidence of this can be seen in EE textbooks and resources that offer students broad examples of environmental issues from around the world, but that are lacking in providing information about locally contextualized issues. Such curriculum can lead students to develop a segmented and disconnected view of how different issues in different communities may be connected and may fail to challenge students to consider how practices in local contexts may impact on the global environment.

Recently, researchers in EE have begun advocating that educators take a situated knowledge approach to teach $\mathrm{EE}$ whereby the environment is understood to be a product of culturally and historically constituted practices and ways of knowing that results in a socially constructed view of the environment (Stapleton, 2020). This position suggests that what the environment is and how it is defined and understood by individuals and groups of people is varying and dependent upon individual and collective experiences with and in the natural 
world. This means that people may hold different understandings about not only what constitutes the environment, but also what priorities need to be addressed when dealing with the environment. Currently, however, there is little research published focusing on students' perceptions about the environment or environmental issues in India. In addition, the government uses a centralized approach to provide a standard EE curriculum to students in every part of the country, regardless of geographical or cultural context. This one-size-fits all approach to EE could be avoided if teachers had knowledge about how their students perceive the environment.

In an effort to address these issues, the researchers in this study collaborated with EE providers in rural India working at a non-governmental organization (NGO), called The Insect, ${ }^{1}$ to learn more about local students' perceptions of the environment. The goal of the study is twofold: 1) share information with NGO educators and local teachers that can be used to develop EE lessons that incorporate students' understandings of the environment and that reflect the environmental concerns facing the students in this region; and 2) learn more about how students in rural India perceive the environment. In the sections that follow, we describe the research questions and study design in more detail.

\section{Research Questions}

This study seeks to explore Indian students' perceptions about the environment and to share these findings with teachers to provide them with information that can help them to develop a more culturally relevant EE program for their students. In this paper, we focus on sharing findings from phase one of our study in which we sought to understand how students in rural Northeast India conceptualized their environment. The following questions framed our inquiry: 1. What images do middle school students in the Chirang District of Assam India have of the environment?

2. What differences and similarities can be found in students' drawings of the environment?

To access students' personal perceptions of the environment, we asked middle school students living in the Chirang District of Assam India to use drawings as representations of their personal images of the environment and to describe these drawings in their own words. We then shared this information with NGO EE providers and teachers who wanted to expand their curriculum materials and activities to reflect the environmental concerns in their local area while also supporting students to make connections with environmental issues at a

1 The Insect is a pseudonym for the NGO that collaborated with us to conduct this research. 
larger scale. Results from this study can support policymakers and EE educators in India to develop more inclusive curriculum materials for students that accounts for students' real concerns about the environment. In the sections that follow, we describe the theoretical and methodological frameworks underpinning our decision to use student drawings for representing mental images about the environment.

\section{Methodological and Theoretical Frameworks}

Our research is grounded in the use of drawings as a methodology for eliciting people's mental images of the world and a phenomenological interpretive approach to understanding students' perceptions about the environment by analyzing students' drawings of the environment. The use of drawings as representations of personal mental models is a common method for eliciting and analyzing personal beliefs (Moseley et al., 2010) and has been used widely in educational research. There is a considerable body of research viewing drawings as an effective means for children to explore and communicate their understandings of emotion, context, and culture (for detailed discussion, see Einarsdottir et al., 2009). As researchers, we view drawing as a non-invasive research method that provides students some control over what they communicate, reduces language barriers for engaging in cross-cultural investigations, and unlike traditional interview methods that require face-to-face and verbal engagement, drawing can minimize student discomfort. In the sections that follow, we introduce research on drawings as representations of personal conceptions.

\subsection{Drawings as Representations of Personal Conceptions}

In the last two decades, researchers in science education have argued the importance for engaging students in activities that elicit representations of students' science understandings through talk (Lemke, 1991; Bruna \& Gomez, 2009), gestures (Roth, 2005), and drawings (Katz, 2017). Analysis of students' illustrations can provide researchers with some insights into the kinds of mental images students hold as representations of concepts and phenomena. Mental images represent a person's thoughts and ideas about how they conceptualize and understand specific phenomena in the world in which they live (Coll \& Treagust, 2003). Drawings serve as physical representations of students' mental images about different concepts. Analysis of students' drawings can offer researchers important insights into how students conceptualize who does science and what it means to learn because students' mental images are shaped by their prior knowledge, past experiences, and observation. Prior studies have 
examined drawings as representations of student-held conceptions about stereotypes about scientists (Chambers, 1983; Farland-Smith, 2012) and their learning environments (Wang \& Tsai, 2012; Hsieh \& Tsai, 2017).

Drawing offers a particular advantage when conducting research with students who have limited literacy skills, preventing them from participating in written assessments or when students do not share the same language as the researchers or who are not comfortable to engage in interviews. This method allows students flexibility to share their perceptions and conceptions, including attitudes and emotions, about a wide variety of topics. The open-ended, creative nature of drawing lends itself to self-expression and thus, provides researchers the opportunity to gain novel insights (Bishop, 2006).

\subsection{Drawings as Representations of Student Conceptions about the Environment}

In this study, we evaluate students' conceptions of the environment as captured through their drawings. In the field of environmental education, children's drawings have long been used to evaluate perceptions and attitudes towards the environment and to probe children's perceptions of specific environmental situations. Early examples include research examining children's perceptions of nuclear power stations (Brown et al., 1987), studies probing children's concerns about taking action to address environmental crises (King, 1995), and studies exploring how children from varying socioeconomic backgrounds perceive the environment in which they live (Barraza, 1999). Researchers have used drawings to assess students' conceptual understandings about specific topics, such as desert environments (Judson, 2011), groundwater (Pan \& Liu, 2018), nature (Dai, 2017), the Earth (Ehrlen, 2009), and the general environment (Moseley et al., 2010). A number of studies have examined students' conceptions about the environment and have found that students broadly tend to conceptualize the environment as a place (Alerby, 2000) that contains living and non-living things (Littledyke, 2004). In addition, studies have found that students tend to view the environment as something that humans are responsible for, can use for their benefit (Loughland et al., 2002), and have harmed (Barraza, 1999).

Analysis of drawings done by children asked to capture on paper what they visualized when they heard the word environment revealed that even young children hold diverse views about what constitutes the environment and they have differing experiences with and perceptions about their relationship with the environment (Alerby, 2000). A more recent study examining students' representations of the concept of sustainability in the context of urban environments (Stokas et al., 2017) found students hold both positive and negative 
expectations for their community's practices related to management and use of natural resources and some students lack a sense of connectedness with nature. Having a clear understanding about how students view the environment and its relationship to their lives can help EE educators to support students to learn how and why they should be active agents in protecting and conserving their natural resources.

\section{Methods}

In this section, we describe the context for this study and the methods used to elicit and analyze students' representations of the environment.

\subsection{Research Setting}

This study took place as part of a larger investigation of teachers and students in the Chirang District of Bodoland in lower Assam, Northeast India, in collaboration with a local NGO, The Insect. Assam is a landlocked state located in northeast India where nearly $75^{-80 \%}$ of the workforce engages in agriculture related employment to produce cash crops such as tea, jute, and bamboo. While Assam is world famous for its tea, the state also grows significant amounts of rice, sugarcane, cotton, and mustard used for domestic consumption. Over the last three millennia, Assam has been part of a number of different kingdoms and is recognized as a culturally, linguistically, and ethnically diverse region. Different ethnic communities within Assam speak around 45 different languages, with the principal language of the state being Assamese, which is regarded as the lingua franca of all of Northeast India. Chirang District, where this study took place, it situated in Bodoland, officially called the Bodoland Territorial Area Districts, which is an autonomous region in the state of Assam where the official language is Bodo.

\subsection{Study Participants}

Participants in this study include the environmental educators working at The Insect, a NGO in the region that works directly with the local government to improve the quality of education in the public schools of the Chirang District. Specifically, The Insect partners with teachers and administrators in local middle schools by sending their own educational workers to schools on a weekly basis to teach lessons about citizenship education, math and science. The first author in this study volunteered as an intern with the NGO for several months during two placements and participated in developing lessons for students and professional development activities for in-service teachers. 
Six schools partnering with The Insect participated in this study. In this paper, we report only on findings from data collected from students. The schools included two Bodo schools, two Assamese schools, and two duallanguage (both Bodo and Assamese) schools. All eighth grade students in each school participated in this study $(n=277)$. Data collection was restricted to grade 8 students because the teachers of these students were participating in a program being offered by the NGO workers. While this is a sample of convenience, it is also a large sample of students from several schools in the district. There is no reason to assume these students' responses would differ significantly from students in other grades in the same school.

Table 1 shows the schools, language groups, and numbers of students in each participating class. Pseudonyms are used to protect the identity of participants in the study.

TABLE 1 List of the schools and the number of students that participated in the study

\begin{tabular}{lll}
\hline School name & Number of students & \\
\hline Bodo School A & & 38 \\
Dual Lingual School A & 29 & 18 \\
Assamese School A & 44 & \\
Dual Lingual School B & 20 & 45 \\
Bodo School B & 37 & 46 \\
Assamese B & 130 (Assamese) & 147 (Bodo) \\
Subtotal & \multicolumn{2}{c}{277} \\
Total number of students & \multicolumn{2}{l}{} \\
\hline
\end{tabular}

All government schools in this district have only one class per grade, regardless of the number of students, with the exception of the dual-language schools where students are divided into two groups based on language.

\subsection{Data Collection-Drawing the Environment}

In this study, we adopted the Draw-an-Environment Test (Shepardson et al., 2007) (see Figure 1) on which students were requested to 1) draw a picture of the "environment" in any form they imagine the environment to be and to 2) to write a short explanation of the drawing.

The Insect NGO educators and middle school teachers in each classroom explained the instructions to students in the language of instruction and in other local languages to ensure students understood the task. The first author 
My drawing of the Environment

Class:

FIGURE 1

Draw an environment worksheet given to students

participated in the data collection process in each classroom and was available for any questions. When evaluating the DAET, researchers use the drawings to assess scientific conceptual knowledge, observational skills, and perceptions. Student writings in their own words are used to clarify their conceptions and the images they have drawn. The written responses also help researchers to validate the meanings of the drawings. The teachers and NGO educators verbally translated the writings into English and the researcher transcribed the translation for each drawing.

\subsection{Content Analysis}

Content analysis was conducted using a deductive approach in which the researchers applied a previously developed categorization method to sort drawings into four overarching categories to help interpret students' conceptions of the environment. Shepardson and colleagues (2007) referred to these as mental models, described below in Table 2.

We offer descriptive analysis of student drawings to show frequency by category and we describe representative samples for each category. The schools in this study are all in the same geographical area, but there are some environmental differences nearby the schools and communities that could influence students' perceptions. For this reason, we also disaggregated findings by school/language. The researchers in this study sorted all 277 drawings independently and then compared results to establish inter-rater reliability. 
TABLE 2 Names and description of mental models to categorize drawings of the environment (as used by Shepardson and colleagues (2007)

\section{Mental model (мм) Descriptions}

MM 1: Natural State

MM 2: Life Supporting

мм3: Human altered

MM4: Harmonious a natural area where only plants and animals (no humans) are found

similar to MM 1, but humans, plants, animals are all together similar to Mм 2, but includes examples of human impact $(+/-)$

similar to MM 2, but, humans and organisms live harmoniously together

Of the 277 drawings, three were classified as invalid because no biotic (living) elements were portrayed. Interestingly, all three of the invalid drawings depicted an image of the Indian national flag (Figure 2).

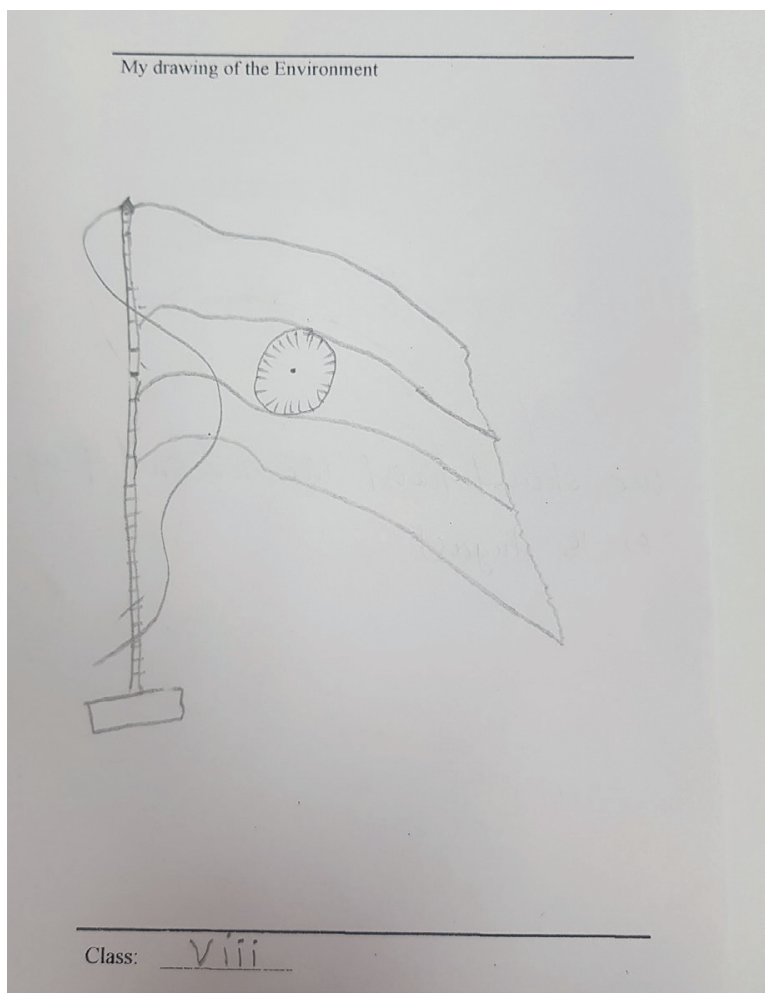

FIGURE 2 Example of an invalid drawing 
In cases where it was difficult to identify a category or the drawing alone was not sufficient for easily classifying into one of the four categories, the written description was used to help clarify. In cases where researchers did not agree on categorization, the drawing was discussed until there was consensus.

\subsection{Ethical Considerations}

Prior to any data collection, ethical approval was obtained from the university human subjects review board. At no time was any personal information recorded. The NGO workers and the classroom teachers conducted the assessment during regular visits to the schools as part of a regular E E lesson. Parental consent was given by parents/guardians of all students to allow for data collection activities. In addition, the Insect also has its own ethical code of conduct that ensures all interactions with students in schools is appropriate and meets expectations of the school, teachers, parents, and NGO. Author 1 was a participant observer during the data collection and worked with the NGO workers and teachers to implement activities.

Findings

The goal of this research was to use Shepardson and colleagues' (2007) mental models categorization tool to identify and sort images drawn of the environment by middle school students in the Chirang District of Assam into different groups and to determine what differences and similarities can be found in these drawings. A total of 277 drawings where analyzed and we found that while there was some variation in students' responses, the majority of images suggest that students view the environment as existing in both a natural state and a human altered state. When exploring student responses based on language, we found that students attending Assamese-speaking schools held more varied views of the environment than students attending Bodo-speaking schools. In the sections that follow, we offer examples of each category, we provide descriptive content analysis of features/elements that appear in students' drawings, and then describe comparative results of student drawings based on school/language use.

\subsection{Mental Model Classifications and Examples \\ 5.1.1 Mental Model 1}

Figure 3 shows examples of students' drawings that were designated Mental Model 1. These drawings had no humans or human modifications; they are purely a place where animals and plants live. 

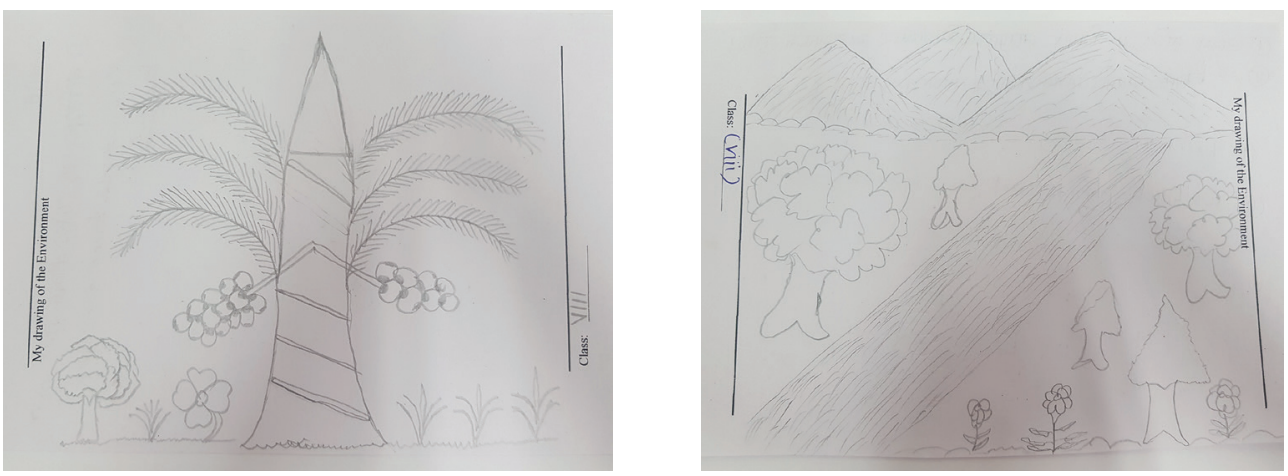

FIGURE 3 Examples of Mental Model 1

\subsubsection{Mental Model 2}

The drawings designated as Mental Model 2 showed nature supporting life. The examples shown in Figure 4 show that trees give oxygen $\left(\mathrm{O}_{2}\right)$, which is needed for life.

\subsubsection{Mental Model 3}

The drawings designated as Mental Model 3 were drawings where humans were seen to have modified the environment (see Figure 5 for examples). This modification could be either human activities such as cutting down trees or planting crops, or buildings or structures such as houses, bridges, or factories.
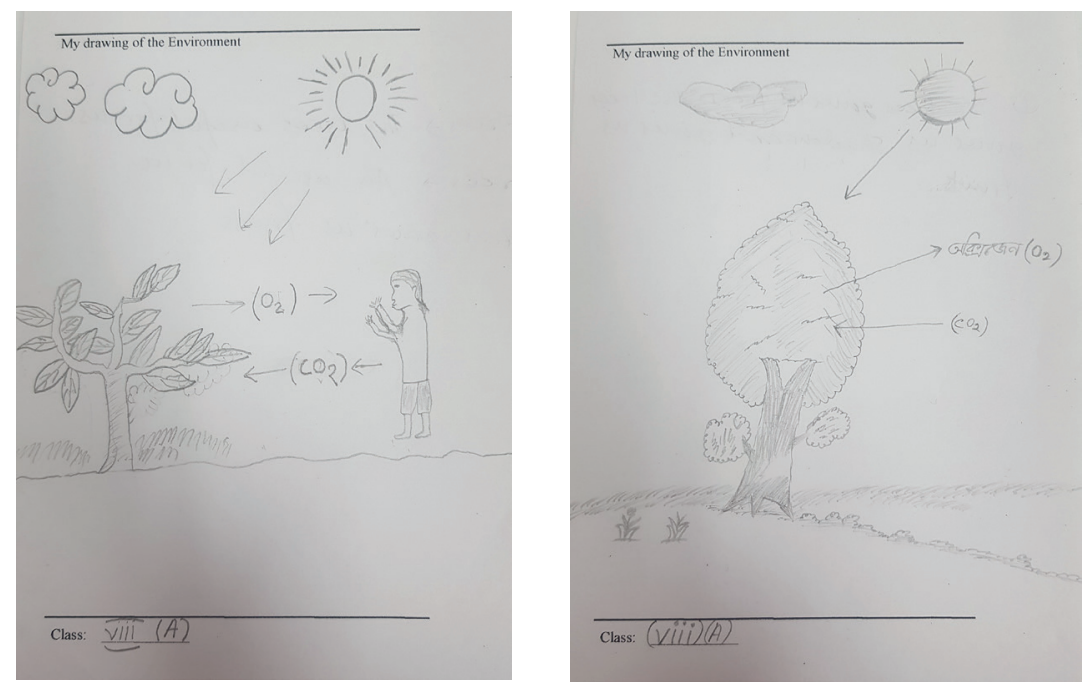

FIGURE 4 Examples of Mental Model 2 

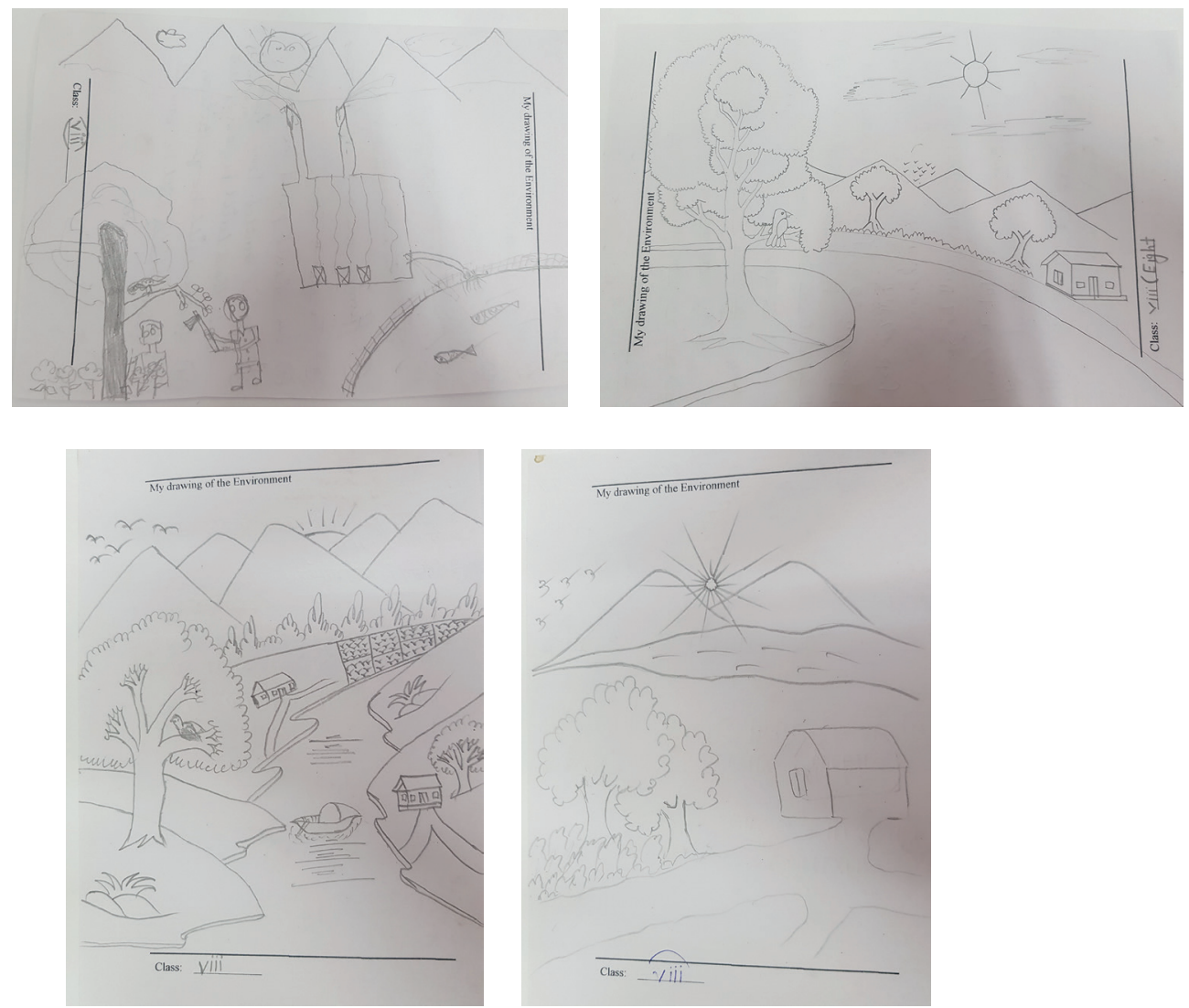

FIGURE 5 Examples of Mental Model 3

\subsubsection{Mental Model 4}

The drawings classified as Mental Model 4 were drawings where humans, plants, and animals were depicted living together (see Figure 6 for an example).

In this final mental model, humans are depicted however the humans have not/are not altering the environment in anyway. Moreover, the environment is not seen as a means of supporting life, as was see in Mental Model 2 (Figure 4). In this mental model, humans and the environment are living together harmoniously.

\subsection{Content Analysis of Features/Elements that Appear in Students}

Table 3 below shows the distribution of students' mental models. Mental Model 3 was portrayed in students' drawings the greatest number of times (62.5\%), followed by Mental Model 1 (30.3\%), Mental Model 2 (4.7\%), and Mental Model 4 (1.4\%). 


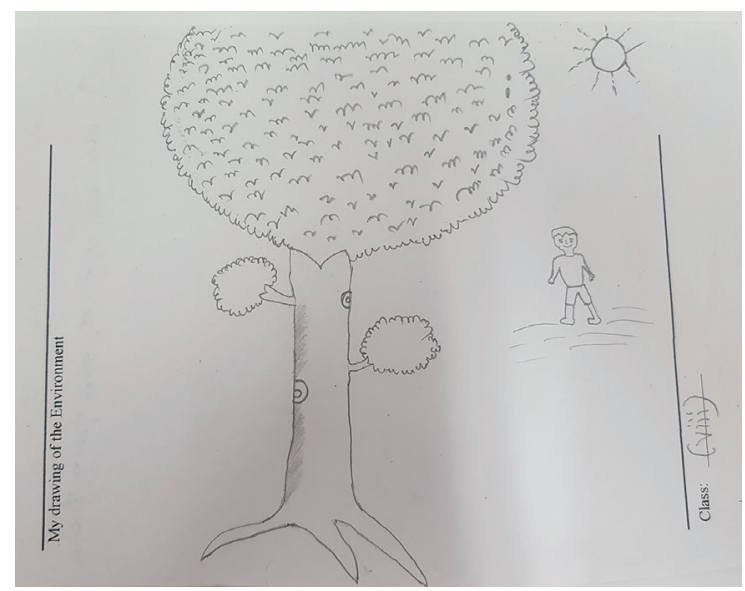

FIgURE 6 Example of Mental Model 4

TABLE 3 Frequency and percentages of students' mental models

\section{Mental model}

MM 1: Natural State

MM2: Life Supporting

MM3: Human altered

MM4: Harmonious

Invalid responses

Total
Frequency

Percentage

84

$13 \quad 4.7 \%$

173

4

3

277
$30.3 \%$

$62.5 \%$

$1.4 \%$

$1.1 \%$

$100 \%$

If we break down the drawings further into the major elements drawn (see Table 4), we can see that almost all ( $96 \%)$ of the students' drawings had some type of flora (trees, grass, flowers, etc.). Remarkably, only $42 \%$ of the drawings depicted fauna (birds, cows, elephants, etc.) of some type. Buildings were depicted in $58.5 \%$ and environmentally unfriendly elements were drawn in only $6.5 \%$ of the drawings.

\subsection{Comparative Analysis of Student Drawings}

The mental model with the highest occurrence was Mental Model 3 (62.5\%). This result may be explained by the fact that the students live in a very homogenous village location and do not have much variation in the environment to which they are exposed. This relatively high frequency shows that students understand that they, humans, are also part of the environment, which is an 
TABLE 4 Frequency and percentages of common elements found in students' drawings of the environment

\begin{tabular}{lll} 
Elements & Frequency & Percentage \\
\hline Flora & 266 & $96 \%$ \\
Fauna & 115 & $42 \%$ \\
Buildings & 162 & $58.5 \%$ \\
Environmentally unfriendly & 18 & $6.5 \%$ \\
\hline
\end{tabular}

important consideration. However, if we take it further and look at the breakdown of what the students drew (Table 4), we can see that while they understood that humans are part of the system, they very rarely drew the harmful aspects of what humans can do to the environment, such as cutting down trees, driving cars, or building factories. Only $6.5 \%$ of the drawings portraying anything environmentally unfriendly.

Figure 7 shows the results when broken down by school. While Mental Model 3 occurred most often in most schools, Assamese School B in an exception, where Mental Model 1 was significantly higher than the other mental models. Only one school, Dual Lingual School B, had all four Mental Models represented. Furthermore, at Dual Lingual A there was a 50/50 split between Mental Models 1 and 3. Bodo School A and Bodo School B showed similar results, where only Mental Models 1 and 3 were produced, and in both cases

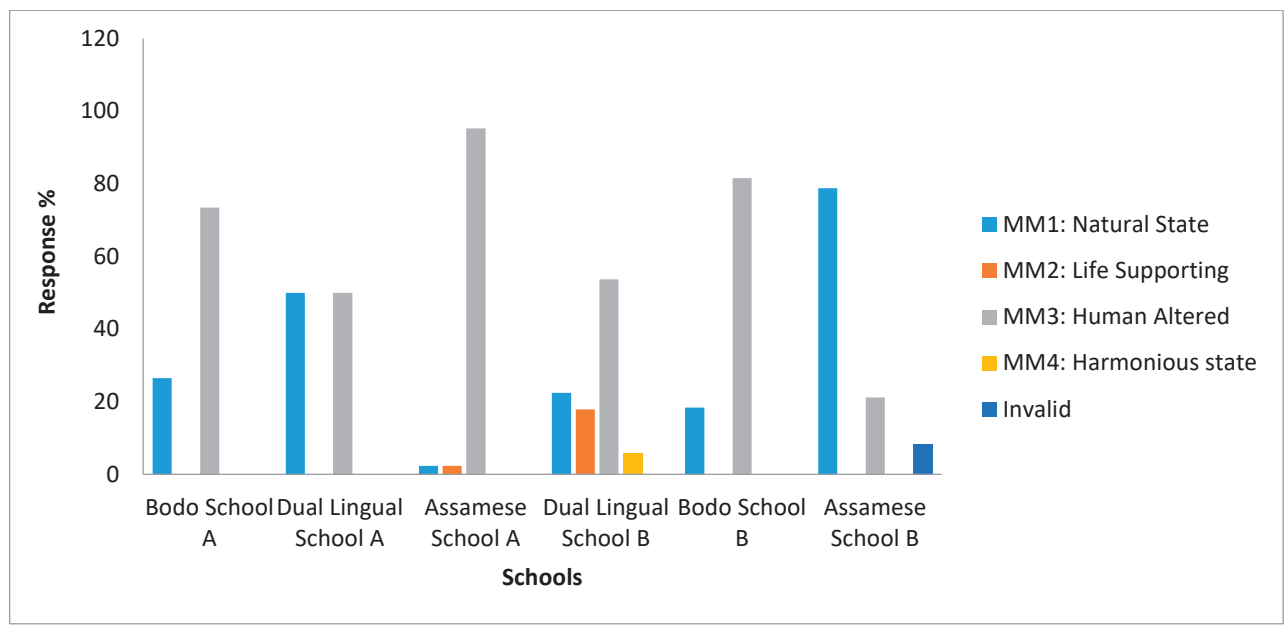

FIGURE 7 Bar graph showing the distributions of mental models based on schools 


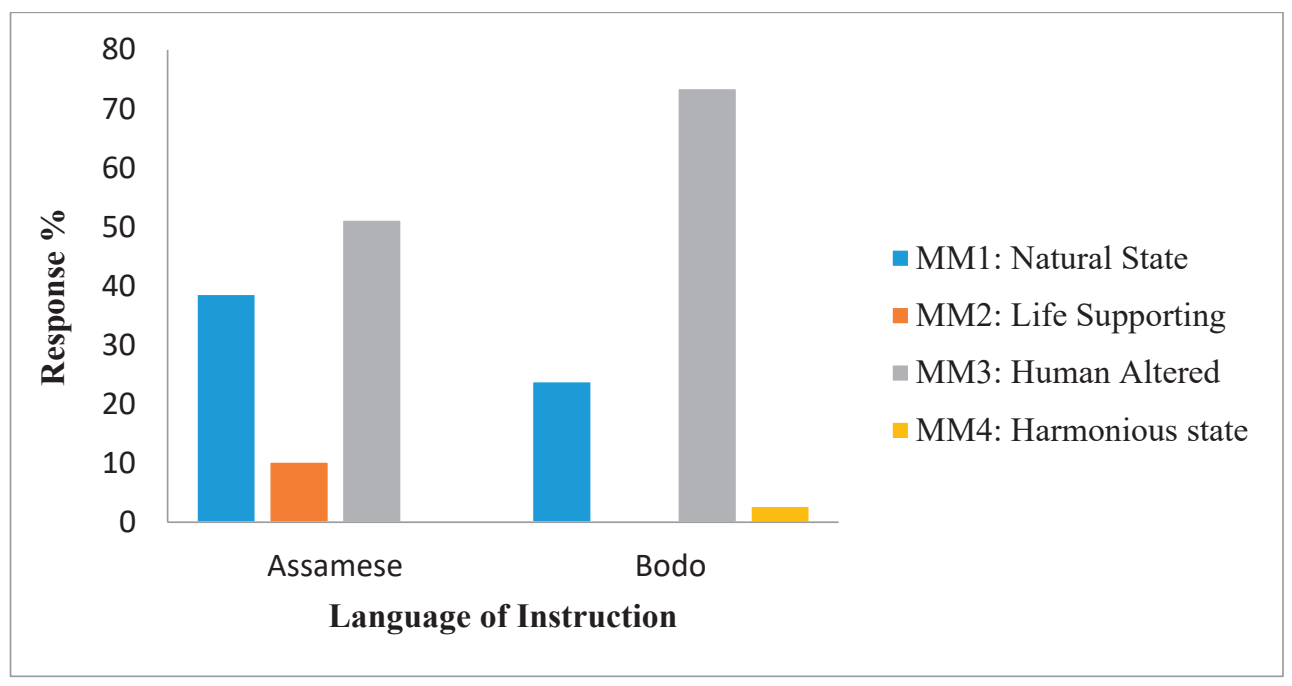

FIGURE 8 Distribution of mental models based on language of instruction

Mental Model 3 occurred more frequently. The government schools in this region divide students and classes based on language, so that even in dual language schools, students were instructed in separate classrooms where teachers used either Assamese or Bodo.

What stands out is that Mental Model 2 (life supporting) was only found in the Assamese language schools and Mental Model 4 (harmonious state) was only found in the Bodo language schools (See Figure 8). The analysis showed there was a very significant association between the language of instruction and students' drawings of the environment. A chi-square test of independence was performed to examine the relation between the language of instruction and the mental model represented. The relation between these variables was significant $\left(\chi^{2}(3, N=274)=28,714, p>.025\right)$. Moreover, a higher percentage of Mental Model 3 was found in Bodo students' drawings than in Assamese students'.

In this section, we discuss some of the findings from our analysis of students' drawings of the environment and we offer implications for this research and the need for additional studies. Specifically, we focus attention on the need for more comparative studies (both domestic and international) for exploring the 
potential for cultural or geographical differences in the ways students experience and conceptualize the environment and we advocate for the development and implementation of more responsive EE curriculum that enhances understanding of context and place.

\subsection{Potential for Cultural or Geographical Influence on Environmental Drawings}

The students in this study live in a very homogenous village in northeast India and have had limited exposure to other natural environments. Many of the students in this study have not traveled outside of their village and have limited exposure to media representations of the environment in other parts of Assam, of India, or the world. While analysis of student drawings show that the majority (62.5\%) of students understand humans are part of the environment and play a role in altering the environment (Mental Model 3), the drawings rarely depicted the ways in which humans can harm the environment by cutting down trees, driving cars, or building/working factories. This result differs from an earlier study of middle school students in United States in which students predominantly depicted the environment as one that appears in a natural state (Mental Model 1) (Shepardson et al., 2007). We also found differences when we compared drawings of students based on language groups. For example, we found that only students enrolled in Bodo language classes drew environments that revealed humans and nature in a harmonious state (Mental Model 4) and only students enrolled in Assamese language classes drew environments representative of nature as life-supporting (Mental Model 2).

In Bodoland, there are only two language options for students attending government schools, either Bodo or Assamese. This means that students who speak Bodo attend the Bodo language schools and all other students, no matter their home language, attend Assamese schools. In this particular region, the Bodo speaking population is mostly Hindu and the students attending the Assamese schools are more diverse with regards to language and religion. However, the NGO educators in this study reported that most of the students attending the Assamese schools were Muslim. Key teachings of both Hindu and Islam religions include the belief that all living things are sacred, including plants and animals, and that humans have a responsibility to protect nature. That the two groups of students in this study represented the environment differently could be a reflection of various factors, including religious beliefs and/or economic and social differences experienced by Assamese speaking students whose families are not considered to be "locals" and who face some challenges in society that could inform how their children make sense of the 
world around them. Differences found across countries and among different groups of students imply that students who live in different geographical locations or who have different backgrounds (cultural/linguistic/racial/religious/ economic) may have different lived experiences that impact on how they view nature and their relationship to the environment.

A review of the literature shows that geographical location can have an impact on how children perceive the environment. Studies comparing urban and rural children's perceptions of the environment in Turkey (Çubukçu, Kahraman, \& Yavaşal, 2018) and in the United States (Machmer, Bruch, \& Kuipers, 2008) show that children tended to notice and value different elements in their surroundings and so their drawings included and emphasized different symbols of local landscapes and the natural environment. Researchers exploring children's mental maps of their own neighborhoods have argued that cultural differences serve as a lens for viewing the world and making children's sense of place such that students with different cultural backgrounds are likely to produce different mental maps of the same physical spaces (Gillespie, 2010). Early (McGlen, Milbrath, \& Yoshi, 1979) and more recent (Dronin \& Bychkova, 2018) international comparative studies have found that geography, culture, and access to information can lead people in different countries to hold not only different perceptions about the environment, but also have different perceptions about the cause and impact of global environmental issues and different beliefs about the roles and responsibilities that individuals and governments should play to address these concerns.

For EE initiatives to be effective, researchers need to have a more complex and complete understanding of how people around the world interact with and conceptualize their local and global environment. This research found that even within one community, there are differences in how members of different groups of students perceive the environment, which could have an impact on how they conceptualize their relationship to nature-including their responsibility to care for it. Furthermore, different groups of students may feel more or less empowered to act to address environmental concerns in their community. While this study offered the NGO educators and local teachers an initial entry to begin exploring these issues more carefully, it is clear that these educators need more support to develop a EE curriculum that can help students to consider why these differences may exist and how awareness about their personal perceptions can support them to think more critically about their relationship with the environment. We believe this is an important first step and we hope to continue to develop this project and work with this community to learn more. 


\subsection{Importance of Responsive Environmental Education (RE E)}

Our analysis of student drawings revealed that students have a good awareness of the environment and they have some shared conceptualizations of the environment in which they live. They understand that humans are a part of the environment and that they in turn have an impact on the environment. However, overall, students' drawings failed to represent the negative impact humans can have on the environment. While living and working in the region near the schools, the first author was repeatedly struck by how much litter was scattered along the roadsides and even scattered all around of school grounds (see Figure 9) and by the number of domesticated animals filling the streets and yards in front of homes, businesses, and schools (see Figure 10).

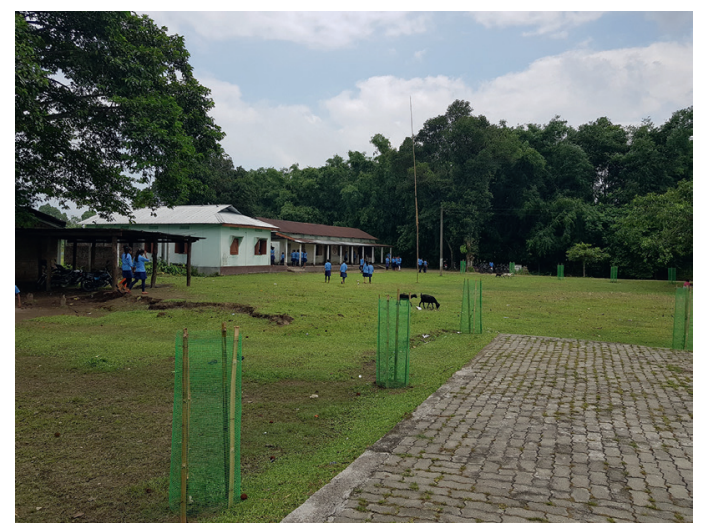

FIGURE 9 The front of a school showing litter and domesticate animals

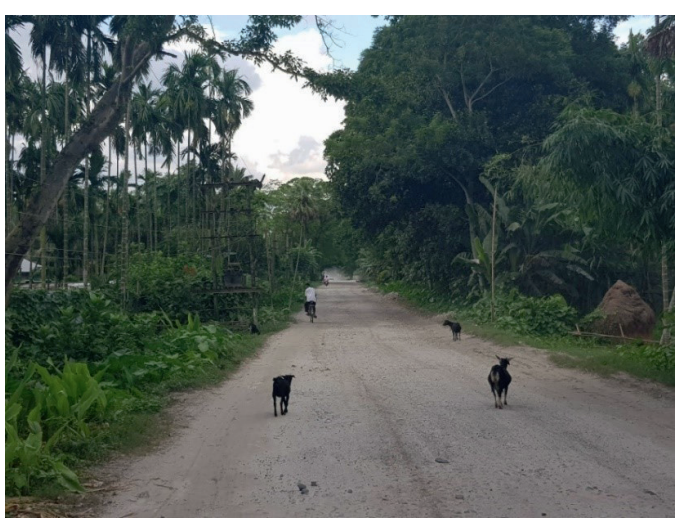

FIGURE 10 One of the main roads in Chirang district showing domesticate goats walking freely around town 
Yet few students in the study portrayed these aspects of the environment in their drawings. In fact, less than half $(42 \%)$ of all students' images included any type of fauna and when they did, students mainly drew birds rather than the goats and cows, which were so prevalent. That students failed to notice the domesticated animals that freely walk around the village and school grounds suggests students may not see them as being "part of the environment."

Although not reported in detail in this paper, the students in this study were also asked to respond to a survey measuring their perceptions about environmental concerns and to participate in a card-sorting activity of ten cards representing images of different environmental issues to rank these issues in order of their concerns. On the survey, about half of all students disagreed that pollution was a bigger concern in developing countries than in developed countries. In addition, students ranked overpopulation, solid waste, and noise pollution as issues of least concern for their community. An independent t-test of student responses based on gender and language showed no significant differences (Sprong, 2020). These findings led us to believe that these students may not fully understand the negative impact that litter has on their environment. In addition, the students may not think about the farm animals seen in their daily lives as being part of the "natural" environment.

In follow-up interviews with teachers and NGO educators, we found they were all shocked that the students did not rank solid waste and over-population as more serious environmental concerns as these are two of the most serious problems facing India. When asked to explain why they thought students did not see these issues as bigger problems, the teachers pointed out that the village and area surrounding the school was actually quite remote and not very densely populated compared to many regions in India. The teachers recognized the importance of having students learn not only about their local context, but also that students needed to be able to situate themselves in relation to the province, country and world. The teachers voiced the need to have their students think more deeply about the environment as a holistic entity that includes all living things, not only those plants and animals that are "wild". In addition, the teachers were concerned that such compartmentalized thinking suggested that some students did not see themselves as part of the environment, which is necessary if students are to reflect on what roles humans must play in protecting and sustaining the environment.

Currently there is a dearth of information about EE or research about teachers' and students' perceptions of the environment in India or in developing countries. Although the worldviews of people in developing countries have 
long been missing from EE studies, the few studies that have been reported have shown that the environmental problems faced by people in developing countries and in marginalized communities are greater than and different from people living in developed countries and people who represent the mainstream or dominate group in their country (Running Grass, 1994; Marouli, 2002). We need more research designed to amplify the voices of people from developing countries so that we can better understand their perceived relationships to the environment. Findings from such studies can be helpful for developing EE curriculum that can target specific learning objectives that can help students to challenge currently held beliefs about the environment. Teachers can use their students' conceptions of the environment as a foundation for constructing a context-specific E E program that incorporates their prior knowledge and experiences and that challenges students to reflect on and develop more complex understandings about the environment and their roles in the environment (Shepardson et al., 2007). The NGO educators and teachers in our study were better positioned to consider what might motivate their students to have more positive attitudes about the environment and develop activities to encourage them to learn about and enact environmentallyfriendly practices in their local community.

A responsive EE curriculum can effectively educate students to develop a positive attitude towards the environment (Roth, 2005) so they can better appreciate and have empathy for environmental concerns, which can support students to change their behavior towards the environment and sustainable development (Eilam \& Trop, 2012). Much research in EE has shown that even when people have knowledge about how to have a positive impact on the environment, they often fail to implement practices necessary to meet their goals, as they are not fully aware of what impact they have. An EE program that supported students to be more agentic about addressing the environmental problems in the community could empower students to make a positive impact on the environment. Moving students toward action and problem solving requires students to be more aware of their environment and to work collaboratively to find solutions that are practical and sustainable. Designing and implementing responsive EE programs have the greatest potential to affect positive changes for the environment and the community members, beyond achieving targeted learning outcomes on assessments. We advocate for the development of more responsive $\mathrm{EE}$ curriculum that engages teachers and students in a dialogue around contextualized content with a goal of empowering learners to act (Freire, 1970). We think this is important world-wide, but 
we especially want to encourage EE educators working in developing countries, to engage local teachers, students and community members to identify what $\mathrm{EE}$ issues are important to know and to learn about in their own contexts. Doing so can expand opportunities for students to be more informed about and become involved in environmental activism to improve their own communities.

\section{7}

\section{Limitations}

While the scope of this study was limited to one district in Northeast India, the findings have given insight to the NGO educators and teachers about how students in this area differ from one another in how they view the environment in which they live. The researchers acknowledge that these drawings are not necessarily complete or accurate representations of students' full understanding of the environment-however, we do believe they offer researchers a kind of snapshot of students' conceptions of the environment. As such, the findings were of great interest to the NGO educators and middle school teachers in this study, and they plan to delve deeper to learn more about their students' understandings about the environment. More intensive data collection and analysis would be needed to consider students' mental models, which are more complex that what can be captured in a single drawing and text description. Nevertheless, these drawings are a useful starting point for the teachers in this study to begin planning and designing lessons that build from what can be learned from these images. More research is needed to understand the effects of implementing responsive $\mathrm{E}$ with students in this study and more comparative studies examining differences among learners in the same regions and in different regions in India and the world are needed to expand our understandings of what conceptions of the environment exist and how these views influence on students' learning and practices related to $\mathrm{EE}$.

\section{Abbreviations}

$\begin{array}{ll}\text { DAET } & \text { Draw-an-Environment Test } \\ \text { EE } & \text { Environmental Education } \\ \text { MM } & \text { Mental Model } \\ \text { NGO } & \text { Non-Governmental Organization }\end{array}$




\section{Acknowledgments}

We wish to express our gratitude to the students who participated in this study as well as the colleagues who supported it. We also thank the non-governmental agency workers and teachers, for their assistance and support throughout this research. Finally, we would like to thank the anonymous reviewers for their helpful suggestions and feedback.

\section{Ethical Considerations}

This research was reviewed and approved by the ethics review committees of both our university and our NGO partner. All data collected for this study was obtained with the necessary clearance from the schools, guardians, and students. In order to protect the identities of all participants, pseudonyms were used.

\section{About the Authors}

Leslie Sprong is an educator and researcher who holds a bachelor of science in Ecology, Environment, and Conservation from the University of Witwatersrand in South Africa and a master's degree in Global Education Cooperation from Seoul National University in Seoul, Republic of Korea. Her research focuses on development and implementation of environmental education that can be used as a tool to support sustainable development. She has a particular interest in exploring how gender influences on teaching and learning of environmental education in K-12 settings.

Sonya N. Martin is an Associate Professor in the Department of Earth Science Education at Seoul National University in Seoul, Republic of Korea. Sonya holds a bachelor's degree in Biology from Bryn Mawr College, and master's degrees in Elementary Education and in Chemistry Education from the University of Pennsylvania in the United States. She also holds a doctoral degree in Science Education from Curtin University in Australia. Her research focuses on identifying science teacher practices that promote learning for diverse students and on promoting the professionalization of science teachers through classroombased participatory research. 


\section{References}

Alerby, E. (2000). A Way of Visualising Children's and Young People's Thoughts about the Environment: A study of drawings. Environmental Education Research, 6:3, 205222, DOI: 10.108 o/13504620050076713

Assaraf, O.B., \& Orion, N. (2010). System thinking skills at the elementary school level. Journal of Research in science teaching, 47(5), 1098-2736.

Barraza, L. (1999). Children's Drawings About the Environment, Environmental Education Research, 5:1, 49-66, DOI: 10.1080/1350462990050103

Bishop, P.A. (2006). The promise of drawing as visual method in middle grades research. Middle Grades Research Journal 1(2): 33-46.

Brown, J.M., Henderson, J., \& Armstrong, M.P. (1987). Children's perceptions of nuclear power stations as revealed through their drawings. Environmental Psychology, 7, 189-199.

Bruna, K.R.., \& Gomez, K. (2009). The work of language in multicultural classrooms: Talking scinece and writing science. Routledge, Inc.

Chambers, D.W. (1983). Stereotypic images of the scientist: The draw-a-scientist test. Science Education, 67(2), 255-265. doi:10.1002/sce.3730670213

Coll, R., \& D. Treagust. (2003). Learners' mental models of metallic bonding. Science Education, 87: 685-707.

Çubukçu, E., Kahraman, D.E. \& Yavaşal, Ö.F. (2105). Comparing the lifestyles and environmental perceptions of rural and urban children: a case study in Turkey. Journal of Housing and the Built Environment, 33, 861-875. https://doi.org/10.1007/ s10901-018-9594-5

Dai, A. (2017). Learning from Children's Drawings of Nature. In P. Katz (Ed.) Drawing for Science Education: An international perspective (pp. 73-86). Sense Publishers.

Darling-Hammond, L., Flook, L., Cook-Harvey, C., Barron, B., \& Osher, D. (2019). Implications for educational practice of the science of learning and development. Applied Developmental Science, 1-44.

Denton, B., \& Sengupta, S. (2019, November 25). India's Ominous Future: Too Little Water, or Far Too Much. New York Times. Retrieved from https://www.google.com/ search?q=who+publishes+the+new+york+times\&rlz=1C1CHBF_enKR849KR849\& oq=who+publish \&aqs=chrome.1.69i57jol 7.8392 joj8\&sourceid $=$ chrome $\&$ ie $=$ UTF- 8

Dronin, N., \& Bychkova, A. (2018). Perceptions of American and Russion environmental scientists of today's key environmental issues: a comparative analysis. Environment, Development, and Sustainability, 20, 2095-2105.

Ehrlen, K. (2009). Drawings as representations of children's conceptions. International Journal of Science Education, 31(1), 41-47. 
Einarsdottir, J., Dockett, S., \& Perry, B. (2009). Making meaning: children's perspectives expressed through drawings, Early Child Development and Care, 179:2, 217-232, DOI: 10.108 o/o3004430802666999.

Eilam, E., \& Trop, T. (2012). Environmental Attitudes and Environmental Behavior: Which Is the Horse and Which Is the Cart? Sustainability, 4(9), 2210-2246.

Farland-Smith, D. (2012). Development and field test of the modified Draw-a-Scientist Test and the Draw-a-Scientist Rubric. School Science \& Mathematics, 112(2), 109-116.

Freire, P. (1970). Pedagogy of the Oppressed. New York: Continuum.

Gillespie, C.A. (2010). How culture constructs our sens eof neighborhood. Mental maps and children's perceptions of place. Journal of Geography, 109, 18-29.

Goldman, D., Assaraf, O.B.Z., \& Shaharabani, D. (2013). Influence of a Non-formal Environmental Education Programme on Junior High-School Students' Environmental Literacy. International Journal of Science Education, 35(3), 515-545. doi:10.1080/ o9500693.2012.749545

Gupta, S.P. (2002). India Vision 2020. New Delhi

Haynes, S. (2019). India Grapples With a Water Shortage as City Residents Reach Their Limits. Time.

Hsieh, W.M., \& Tsai, C.C. (2017). Exploring students' conceptions of science learning via drawing: A cross-sectional analysis. International Journal of Science Education, 39, 274-298.

Irfan, U. (2017). How Delhi became the most polluted city on Earth. Vox, p. 348. Retrieved on June 1, 2020 from https://www.vox.com/energy-and-environment/ 2017/11/22/166668o8/india-air-pollution-new-delhi

Judson, E. (2011). The impact of field trips and family involvement on mental models of the desert environment. International Journal of Science Education, 33(11), 1455-1472.

Katz, P. (2017). Drawing for Science Education: An international Perpective. Sense Publishers.

King, D.L. (1995). Doing their share to save the planet: Children and environmental crisis. Rutgers University Press.

Kollmuss, A., \& Agyeman, J. (2002). Mind the gap: why do people act environmentally and what are the barriers to pro-environmental behavior? Environmental Education Research, 8(3), 239-26o.

Ladson-Billings, G. (1995). But That's Just Good Teaching! The Case for Culturally Relevant Pedagogy. Theory Into Practice, 34(5), 159-165.

Lemke, J.L. (1991). Talking Science: Language, learning and values. Ablex.

Littledyke, M. (2004). Primary children's views on science and environmental issues: examples of environmental cognitive and moral development. Environmental Education Research, 10, 217-235. 
Liu, S.-C., Lin, H.-S., \& Tsai, C.-Y. (2O2O). Ninth grade students' mental models of the marine environment and their implications for environmental science education in Taiwan. The Journal of Environmental Education, 51(1), 72-82.

Loughland, T., Reid, A., \& Petocz, P. (2002). Young people's conceptions of environment: a phenomenographic analysis. Environmental Education Research, 8, 187-197

Loughland, T., Walker, K., \& Brady, L. (2000). The Social Cultural Influences on Environmental Understandings of NSW School Students: The First Line of Analysis. Paper presented at the Australian Association for Research in Education, Sydney, Australia.

Machemer, P.L., Bruch, S.P., \& Kuipers, R. (2008). Comparing rural and urban children's perceptions of an ideal environment. Journal of Planning Education and Research, 28(2), 143-16o.

Marouli, C. (2002). Multicultural Environmental Education: Theory and practice. Canadian Journal of Environmental Education, 7(1), 26-42.

McGlen, N.E., Milbrath, L.W., \& Yoshi, H. (1979). Cultural differences in perceptions of environmental problems. Technological Forecasting and Social Change, 14(2), 97-114.

Moseley, C., Desjean-Perrotta, B., \& Utley, J. (2010). The Draw-An-Environment Test Rubric(DAET-R): exploring pre-service teachers' mental models of the environment, Environmental Education Research, 16:2, 189-208, DOI: 10.1080/13504620903548674

Pachauri, R.K. (2004). The future of India's economic growth: the natural resources and energy dimension. Futures, 36(6), 703-713.

Pan, Y.T., \& Liu, S.C. (2018). Students' understanding of a groundwater system and attitudes towards groundwater use and conservation. International Journal of Science Education, 40(5), 564-578.

Ravindranath, S. (2016). Environmental Education in India-The Shifting Paradigm. In R.N. Gorana \& P.R. Kanaujia (Eds.), Reorienting Educational Efforts for Sustainable Development, Schooling for Sustainable Development. Netherlands: Springer.

Roth, W.M. (2005). Talking Science: Language and leanring in scinece classrooms. Rowman \& Littlefield Publishers, Inc.

Running Grass. (1994). Towards a Multicultural Environmental Education. Clearing, 84, 9-12.

Sauvé, L. (1996). Environmental education and sustainable development: A further appraisal. Canadian Journal of Environmental Education, 1, 7-34.

Shepardson, D.P., Wee, B., Priddy, M., \& Harbor, J. (2007). Students' mental models of the environment. Journal of Research in science teaching, 44(2), 327-348.

Siddiqui, T.Z., \& Khan, A. (2015). Environment Education: An Indian Perspective. Research Journal of Chemical Sciences, 5(1), 1-6.

Sonowal, C. (2009). Environmental education in schools: the Indian scenario. Journal of human ecology, 28(1), 15-36. 
Sprong, L. (2020). Desigining culturally relevant environmental education in North East India via a field-based collaborative approach. [Unpublished master's thesis]. Seoul National University, Seoul, Republic of Korea.

Stapleton, S.R. (2020). Toward critical environmental education: a standpoint analysis of race in the American environmental context, Environmental Education Research, 26:2, 155-170. DOI: 10.1080/13504622.2019.1648768

Stokas, D., Strezou, E., Malandrakis, G., \& Papadopoulou, P. (2017). Greek primary school children's representations of the urban environment as seen through their drawings, Environmental Education Research, 23:8, 1088-1114, DOI: 10.1080/ 13504622.2016.1219316

Wang, H.Y., \& Tsai, C.C. (2012). An exploration of elementary school students' conceptions of learning: a drawing analysis. The Asia-Pacific Education Researcher, 21(3), $610-617$. 